\title{
A New Discriminative Criterion for the Development of Franz Diffusion Tests for Transdermal Pharmaceuticals
}

\author{
Bram Baert ${ }^{1}$, Jente Boonen ${ }^{1}$, Christian Burvenich ${ }^{2}$, Nathalie Roche ${ }^{3}$, Filip Stillaert ${ }^{3}$, Philipe Blondeel ${ }^{3}$, Jan Van Bocxlaer ${ }^{4}$ \\ and Bart De Spiegeleer ${ }^{1,}$ \\ ${ }^{1}$ Drug Quality and Registration (DruQuaR) group, Faculty of Pharmaceutical Sciences, Ghent University, 9000 Ghent, \\ Belgium. ${ }^{2}$ Department of Physiology and Biometrics, Faculty of Veterinary Medicine, Ghent University, 9820 Merelbeke, \\ Belgium. ${ }^{3}$ Department of Plastic and Reconstructive Surgery, University Hospital Gent, 9000 Ghent, Belgium. \\ ${ }^{4}$ Laboratory of Medical Biochemistry and Clinical Analysis, Faculty of Pharmaceutical Sciences, Ghent University, 9000 \\ Ghent, Belgium.
}

Received, October 5, 2009; Revised, March 19, 2010; Accepted, May 31, 2010; Published, June 27, 2010.

\begin{abstract}
PURPOSE. In vitro skin/membrane permeation profiling of topical pharmaceuticals is an important overall quality attribute in the evaluation of product consistency and it is also used for IVIVR (in vitro - in vivo relationship) purposes in product development and change control. Franz diffusion cell (FDC) experiments are emerging as a generally accepted methodology in this field, where the choice of operational conditions requires a data-supported justification towards the discriminating power of the test. A response function is therefore proposed to objectively quantify the discriminating power. METHODS. We evaluated the usefulness of the proposed response function by studying one of the operational conditions, i.e. the influence of receptor medium composition, on the FDC in vitro penetration behaviour of the model compound testosterone formulated in four different topical preparations, using both artificial membranes and dermatomed human skin. A second application is a FDC test system for spilanthol. RESULTS. From the obtained cumulative amount of the active (testosterone or spilanthol) in the receptor fluid versus time curves, the permeability coefficient Kp of testosterone from each formulation was calculated. The evaluation of the discriminating power of the different media was performed using our new objective response function based upon an equal spread criterion of normalised Kp values. CONCLUSION. The proposed new criterion was found to be useful for the rational design of an in vitro diffusion test for transdermal pharmaceuticals. We demonstrated significant differences in discriminating power between the different media used: (a) for testosterone-containing formulations, it was shown that HPBCD-containing media are more discriminative compared to ethanol- or BSA-containing media; (b) for spilanthol-containing formulations, PBS containing formulations also gave better discriminating results than ethanol-based receptor media.
\end{abstract}

\section{INTRODUCTION}

The commercialization of transdermal drug delivery systems (TDS) like patches and gels has resulted in diverse products (1) such as nitroglycerin for angina pectoris, scopolamine for motion sickness, fentanyl for pain control, nicotine for smoking cessation, estrogen for hormone replacement therapy, testosterone for male hypogonadism, clonidine for hypertension, lidocaine for topical anaesthesia, and ethynylestradiol for contraception. Over the last decades, transdermal drug delivery has become increasingly popular for many reasons (2): the availability of well-characterized formulation technology (3), the development of a biopharmaceutical, pharmacokinetic and pharmacodynamic science base to allow definition and study of important safety and efficacy issues that are related to TDS, the opportunities afforded by TDS for better patient compliance and more consistent and reliable drug concentrations over protracted dosing periods, a high degree of acceptance by both patients and health care professionals and the development or extension of market exclusivity for off-patent drugs or drugs that are losing patent or exclusivity protection.

Corresponding Author: B. De Spiegeleer, Drug Quality and Registration (DruQuaR) group, Faculty of Pharmaceutical Sciences, Ghent University, Harelbekestraat 72, B-9000 Ghent, Belgium; E-mail address: Bart.DeSpiegeleer@UGent.be 
As a result, the pharmaceutical industry is investing increasing amounts of money and resources on the development of new products that reversibly overcome the skin barrier.Although a new transdermal product is only of value if the clinical pharmacokinetic profile delivers the appropriate pharmacodynamic response needed for the treatment of the patient, preclinical assessments strongly guides the product development. These include as well in vitro experiments for determining the flux of the compound across skin or membranes during feasibility studies, as in vivo evaluation in animal models (4). The aim of the in vitro experiments in transdermal delivery is to evaluate the penetration of a molecule through the skin. Typically, this is achieved by using a variety of skin diffusion cells and different experimental protocols. There have been numerous recommendations, and some of them have been selected as guidelines by both regulatory entities and committees of interested parties. The most widely known of these guidelines are "Guideline Number 428 on the Conduct of Skin Absorption Studies" by the Organization for Economic Cooperation and Development (OECD) (5), the European Centre for Ecotoxicology and Toxicology of Chemicals (EXETOC) workshop on "Methods for assessing percutaneous penetration" (6), the "Guidelines for Percutaneous Penetration / Absorption" by the European Cosmetic Toiletry and Perfumery Association (COLIPA) (7), the American Association of Pharmaceutical Scientists/Food and Drug Administration (AAPS/FDA) workshop on the performance of in vitro skin penetration studies (8) and the FDA "Guidance for the Industry on Non-sterile Semisolid Dosage Forms" (9). Irrespective of the guidance followed, the techniques used must be carefully considered as several variables such as the type of cell system, the skin source, skin integrity and viability, skin preparation, composition of receptor fluid and even the way as results are calculated can influence the outcome and final conclusions (10).

Determination of the release rate of the active pharmaceutical ingredient (API) and/or specific excipients from the formulation, i.e. its diffusion in and through a biological or artificial membrane contacting a receptor fluid, is not only an important parameter for characterizing its transdermal behaviour, but it can also be considered as a global overall quality attribute which is valuable in the development of a suitable formulation or in the evaluation of possible changes in formulation composition (11), production parameters and shelflife stability. Therefore, the regulatory health authorities are generally requesting these diffusionrelease tests in the pharmaceutical dossier submitted to obtain the marketing authorisation. The following points should be considered when developing the in vitro release procedure for dermatological products (12): (a) the method(s) developed should assure batch-to-batch quality for the product, (b) the method should be general enough and should be applicable to all products that are (and will be) marketed, (c) the method should be discriminative enough to detect manufacturing changes that (may) influence product performance and (d) the method should be simple, reliable, reproducible and capable of automation. However, the development of such a global functionality quality test is currently often a matter of discussion due to a certain lack of standardisation, missing generally accepted criteria, incomplete understanding of fundamental theory and its applications, regulatory immaturity and the different objectives which are sometimes mixed up (quality-consistency versus in-vitro-in-vivo correlations). Whatever the context, however, a key aspect is the discriminating power of the test (13), i.e. the ability to distinguish different preparations as separate items. Therefore, we propose a new criterion assessing the discriminating power between different FDC-tests, based on experimentally obtained $\mathrm{Kp}$ values. The applicability of this criterion is demonstrated by the systematic evaluation of different FDC receptor media on the transdermal and transmembrane behaviour of the test compound testosterone, previously defined as a suitable model compound for skin penetration studies (14). A second application given here is the skin FDC test system for spilanthol containing formulations.

\section{METHODS}

\section{Products examined}

Three testosterone-containing topical products were purchased from the Ghent university hospital pharmacy: Testim ${ }^{\circledR} 50 \mathrm{mg}$ gel (Ipsen, Merelbeke, Belgium), Androgel ${ }^{\circledR} 50 \mathrm{mg}$ gel (Laboratoires Besins International, Paris, France) and Tostrex ${ }^{\circledR}$ $2 \%$ gel (Strakan, Tredegar, UK). Androtiv ${ }^{\circledR} 2 \%$ gel 
(Anastore, Geneva, Switzerland) was obtained from the internet.

\section{Reagents}

$0.01 \mathrm{M}$ phosphate buffered saline (PBS) and $\mathrm{CaCl}_{2} \cdot \mathrm{H}_{2} \mathrm{O}$ were purchased from Sigma (St. Louis, MO, USA). Bovine serum albumin (BSA), $\mathrm{Na}_{2} \mathrm{SO}_{4}$, $\mathrm{KH}_{2} \mathrm{PO}_{4}, \mathrm{~K}_{2} \mathrm{HPO}_{4}, \mathrm{MgSO}_{4}$ and $\mathrm{NaOH}$ were bought from Merck (Darmstadt, Germany). $\mathrm{NaCl}, \mathrm{KCl}$, $\mathrm{MgCl}_{2} \cdot 6 \mathrm{H}_{2} \mathrm{O}$ and $\mathrm{NaHCO}_{3}$ were obtained from UCB (Leuven, Belgium). HPLC gradient grade acetonitrile and methanol came from Fisher Scientific (Leicestershire, UK). LC-MS grade formic acid and HPLC-grade testosterone were purchased from Fluka (Buchs, Switzerland). Hydroxypropyl- $\beta$-cyclodextrine (HPBCD) and $\mathrm{HCl}$ were obtained from Acros Organics (Geel, Belgium). Ethanol, denatured with up to $5 \%$ ether, was bought from Chem Lab (Zedelgem, Belgium). Water was purified using an Arium 611 purification system (Sartorius, Göttingen, Germany) resulting in ultrapure water of $18.2 \mathrm{M} \Omega . \mathrm{cm}$ quality.

\section{Liquid chromatography}

The testosterone content in the receptor fluid was assayed using a validated HPLC-UV method (15). Briefly, the HPLC apparatus consisted of a Waters Alliance 2695 separation module and a Waters 2996 photodiode array detector (DAD) controlled by Empower 2 software (all Waters, Millford, USA). $20 \mu \mathrm{L}$ of each sample was injected onto a Lichrospher $100 \mathrm{RP} \mathrm{C}_{18}(125 \mathrm{~mm} \times 4 \mathrm{~mm}, 5 \mu \mathrm{m}$ particle size) column (Merck, Darmstadt, Germany) maintained at $30^{\circ} \mathrm{C}$. Testosterone was eluted by a degassed isocratic mobile phase consisting of a mixture of $50 \%$ (A) $0.1 \% \mathrm{~m} / \mathrm{V}$ formic acid in water, and $50 \%$ (B) $0.1 \% \mathrm{~m} / \mathrm{V}$ formic acid in acetonitrile at a flow rate of $1 \mathrm{ml} / \mathrm{min}$. UV detection was done at $254 \mathrm{~nm}$.

\section{Preparation of receptor media}

Ethanol $/ \mathrm{H}_{2} \mathrm{O}(30: 70, \mathrm{~V} / \mathrm{V})$ was used as a reference receptor medium. Phosphate buffered saline was prepared according to the suppliers (Sigma) instructions, resulting in a $0.01 \mathrm{M}$ solution at $\mathrm{pH}$ 7.4. Artificial human sweat (SS) was prepared according to Shimamura (16). Simulated body fluid (SBF) was prepared as described by Dorozhkin (17). The exact composition is given in Table 1. To assure a good solubility of testosterone, a solubilizer was added. This was either $5 \% \mathrm{~m} / \mathrm{V}$ BSA or $0.5 \% \mathrm{~m} / \mathrm{V}$ HPBCD.

Table 1. Composition of the physiological receptor media used (in $\mathrm{mM}$ ).

\begin{tabular}{llll}
\hline Component & PBS & SS & SBF \\
\hline $\mathrm{NaCl}$ & 138.00 & 49.96 & 136.80 \\
$\mathrm{KCl}$ & 2.70 & - & 3.00 \\
$\mathrm{CaCl}$ & - & 0.15 & 2.50 \\
$\mathrm{MgSO}_{4}$ & - & 1.00 & - \\
$\mathrm{MgCl}_{2}$ & - & - & 1.50 \\
$\mathrm{Na}_{2} \mathrm{SO}_{4}$ & - & - & 0.50 \\
$\mathrm{NaHCO}_{3}$ & - & - & 4.20 \\
$\mathrm{KH}_{2} \mathrm{PO}_{4}$ & 1.43 & 7.50 & 1.00 \\
$\mathrm{Na}_{2} \mathrm{HPO}_{4}$ & 8.57 & - & - \\
\hline
\end{tabular}

\section{Determination of testosterone solubility in the receptor media}

Excess testosterone was added to $2 \mathrm{ml}$ of each receptor medium used and the mixture was incubated for 48 hours at $32^{\circ} \mathrm{C}$ with continuous shaking. The undissolved testosterone was removed by temperature-controlled centrifugation at 20000 g. $500 \mu \mathrm{L}$ of the clear supernatant was transferred to a new tube and an equal volume of acetonitrile was added. After 10 minutes of shaking at room temperature, the samples were centrifuged for 10 $\min$ at $20000 \mathrm{~g}$ and the clear supernatant was transferred into glass HPLC vials. All tubes and pipettes used were preheated to $32^{\circ} \mathrm{C}$ in an oven. All experiments were performed in six-fold, except for $\mathrm{EtOH} / \mathrm{H}_{2} \mathrm{O}$ as a solvent, where only three measurements were made.

\section{Permeation study}

The permeation of testosterone through both human skin and the artificial membrane was determined using static Franz diffusion cells (Logan Instruments Corp., New Jersey, USA) with a calibrated receptor compartment of $5 \mathrm{~mL}$ equipped with a sampling port. All conditions were performed in triplicate using a randomized blocked design. For the skin experiments, excised human skin from three different female patients $(52 \pm 7$ years old, mean \pm standard deviation), who had undergone an abdominoplasty procedure, was used in such a way that each block of experiments was performed using skin from one donor. After 
cleaning the skin with $0.01 \mathrm{M}$ PBS pH 7.4 and removal of the subcutaneous fat, the skin samples were wrapped in aluminium foil and stored at $-20^{\circ} \mathrm{C}$ for not longer than 3 months. Just before the start of the experiments, the skin samples were thawed and dermatomed to a pre-set thickness of $400 \mu \mathrm{m}$. The experimentally obtained thickness was determined using a micrometer (Mitutoyo, Tokyo, Japan). Skin samples or hydrophilic mixed cellulose esters filter sheets with $0.05 \mu \mathrm{m}$ pore size (VMWP; Millipore, Schwalbach, Germany) were sandwiched between the donor (upper) and the receptor (lower) chambers of the diffusion cell. The receptor compartment was filled with receptor medium, making sure all air under the skin/membrane was removed. The whole assembly was fixed on a magnetic stirrer and the solution in the receptor compartment was continuously stirred using a Teflon coated magnetic stirring bar $(400 \mathrm{rpm})$. Before starting the skin experiments, skin impedance with PBS in the donor chamber was measured using an automatic microprocessor controlled LCR Impedance Bridge (Tinsley, Croydon, U.K.) to ensure that there was no skin damage. Skin pieces with an impedance value below $20 \mathrm{k} \Omega$ were discarded and replaced. A quantity of the formulation corresponding to $3 \mathrm{mg}$ of testosterone was topically applied to the surface of the skin/membrane and carefully spread to achieve complete coverage. Smaller quantities of the formulations did not guarantee the full skin coverage. The donor compartment was then covered with parafilm (American National Can ${ }^{\mathrm{TM}}$, Chicago, USA) and the temperature of the receptor compartment was kept at $32 \pm 2{ }^{\circ} \mathrm{C}$ by a water jacket. The available diffusion area was $0.64 \mathrm{~cm}^{2}$. Samples $(200 \mu \mathrm{L})$ were drawn at regular time intervals from the sampling port $(0,0.5,1,1.5,2,4$, $8,12,18,21$ and 24h) and were immediately replaced by $200 \mu \mathrm{L}$ fresh solution. The analytically determined testosterone assay values were correspondingly corrected for the replenishments.

\section{Data analysis}

The skin permeation parameters were calculated from the plot of cumulative amount testosterone permeated as a function of time. Steady-state flux (J) was obtained from the slope of the linear portion of the curve. The permeability coefficient Kp was calculated using the following equation:

$$
K p=\frac{J}{C_{d}}
$$

where $C_{d}$ is the concentration of the drug in the dose formulation.

In case of the artificial membranes, a bending point was observed, i.e. two different slopes (Jvalues). Hence, an initial $\mathrm{Kp}$ from the first part of the curve and a final $\mathrm{Kp}$ from the second part of the curve was calculated.

All $\mathrm{Kp}$ values thus obtained ( $i$ from 1 to 20 for each of the 3 membrane systems: skin, initial- and final artificial membrane) were rescaled within each membrane system using the following normalization equation, resulting in a distribution between 0 and 1:

$K^{\prime} p_{i}=$ normalised $K p_{i}=\frac{K p_{i}-K p_{\min }}{K p_{\max }-K p_{\min }}$

where $K^{\prime} p_{i}$ is the normalised $K p$ value for experiment $i, \mathrm{Kp}_{\min }$ and $\mathrm{Kp}_{\max }$ are the minimal and maximal values for $\mathrm{Kp}$ that were found over the total number of experiments $(n)$. An overall response function $\mathrm{F}(\mathrm{Kp})$ reflecting the formulationdiscriminating power of the system was defined as the percentage equal-spread of the normalised Kpvalues obtained for the different formulations (in our model study: $\mathrm{n}=4$ ), using the following formula:

$$
F(K p)=\frac{\prod_{i=1}^{n-1}\left(K^{\prime} p_{i+1}-K^{\prime} p_{i}\right)}{\left(\frac{1}{n-1}\right)^{n-1}} \times 100 \%
$$

where the denominator (in our study: $0.33^{3}$ ) represents the ideal situation where spreading of the normalised $\mathrm{Kp}$ values is maximal, and hence reflecting the maximal discriminating power between the different formulations used in the study.

There is usually an interval between the start of the experiment and the steady state being reached. This lag-time is derived from the graph of cumulative absorbed dose versus time: it is the intercept (on the time axis) of the tangent to the linear part of the absorption profile.

\section{Spilanthol application}

A recent study has evaluated the transdermal behaviour of the N-alkylamide spilanthol. Three 
different formulations were compared on three different FDC test systems, differing in the receptor fluid (PBS, PBS $+0.5 \% \mathrm{~m} / \mathrm{V}$ HPBCD and $\left.\mathrm{EtOH} / \mathrm{H}_{2} \mathrm{O}(30 / 70, \mathrm{~V} / \mathrm{V})\right)$. Full experimental details and the transdermal results obtained are given in references $(18-19)$.

\section{RESULTS}

We used our criterion in a study evaluating the receptor phase composition. The solubility of the test compound should be sufficiently high to prevent slowing down the flux. Typically, the receptor fluids used are physiological saline or phosphate buffered solutions. If necessary, these solutions are complemented with a solubilizer. However, due to interactions with the skin, the receptor fluid itself can change the transdermal behaviour of the test compound. Hence, this operational variable in FDC tests can influence the discriminative power of the test system.

\section{Testosterone solubility in the receptor media}

Before starting the skin penetration studies, the solubility of testosterone at $32^{\circ} \mathrm{C}$ (i.e. the physiological skin temperature (5)) was determined for each receptor medium. Results are given in Table 2. Without solubilising agent added, testosterone solubility was very low, ranging between 67 and $87 \mu \mathrm{g} / \mathrm{mL}$. Therefore, these media without solubilising agents were not used as a receptor fluid. Ethanol-based receptor media are historically quite often used in this kind of studies, and testosterone was highly soluble in the $\mathrm{EtOH} / \mathrm{H}_{2} \mathrm{O} \quad(30 / 70, \mathrm{~V} / \mathrm{V})$ receptor medium. However, because the use of organic solvents is considered not well-suited as a biocompatible receptor medium in product development and establishing IVIVR (20) resulting in a regulatory reluctance to accept these organic solvent based receptor media, different other physiological buffers were evaluated as receptor media as well. However, due to the very low solubility of testosterone in purely aqueous systems, the addition of a solubilising additive was required. In compliance with the OECD guideline 428 and considering the fact that a concentration of $50 \mathrm{~g} / \mathrm{L}$ is generally accepted to be the mean albumin concentration in human serum (21), 5\% m/V BSA was used. As an alternative, addition of HPBCD as a solubilizer was evaluated as well. The solubility of testosterone at $32^{\circ} \mathrm{C}$ in PBS was determined at different HPBCD concentrations ranging from 0 till $5 \% \mathrm{~m} / \mathrm{V}$. A linear relationship between the testosterone solubility and the percentage HPBCD added was found $\left(\mathrm{R}^{2}=\right.$ 0.9991 ). A working concentration of $0.5 \% \mathrm{~m} / \mathrm{V}$ HPBCD was chosen, as this gave solubility results in the range of the physiological $5 \% \mathrm{~m} / \mathrm{V}$ BSA. The ratio of testosterone solubility at $32^{\circ} \mathrm{C}$ to the maximum amount of testosterone found in the receptor fluids of the skin and of the initial flux through the artificial membrane was minimally five (i.e. for $\mathrm{SS}+0.5 \% \mathrm{HPBCD}$ ): this value is sufficiently high to assure that solubility of the active ingredient in the receptor phase was not the rate limiting step for transdermal and initial transmembrane penetration, which was experimentally confirmed by the linear kinetics.

\section{Franz diffusion cell experiments using human skin}

In our development of a regulatory acceptable, i.e. a data-supported, justified and discriminating test method, we used four model formulations from different origin/supplier/composition which are thus expected to show differences in their diffusion behaviour. Our experimental data are given in Table 3. For all experimental conditions, a steady state linear part was reached $\left(\mathrm{R}^{2}\right.$ values ranging from 0.9566 to 0.9971 ) and therefore transdermal parameters for each condition could be calculated using the previously given formulae (Figure 1). As two formulations have a label claim of $2 \% \mathrm{~m} / \mathrm{m}$ (Androtiv ${ }^{\circledR}$ and Tostrex ${ }^{\circledR}$ ) and two formulations are $1 \% \quad \mathrm{~m} / \mathrm{m} \quad\left(\right.$ Androgel ${ }^{\circledR}$ and Testim $^{\circledR}$ ), the permeability coefficient $\mathrm{Kp}$ is a more appropriate evaluation tool compared to an absolute permeated quantity, as $\mathrm{Kp}$ takes the concentration effect into account. Moreover, Kp reduces all the different experimental points into one concentrationstandardised flux-value, contrasting a one-timepoint like e.g. the cumulative amount penetrated after 24 hours. When the acceptor medium contained BSA, the rank order of transdermal permeation was as follows (from high to low): Tostrex $^{\circledR}$, Androgel $^{\circledR}$, Androtiv ${ }^{\circledR}$ and Testim ${ }^{\circledR}$. When $0.5 \% \mathrm{~m} / \mathrm{V}$ HPBCD was present in the receptor chamber, Tostrex ${ }^{\circledR}$ and Androgel ${ }^{\circledR}$ still showed the highest permeation, but testosterone penetration from Androtiv ${ }^{\circledR}$ was lower than from Testim $^{\circledR}$. 

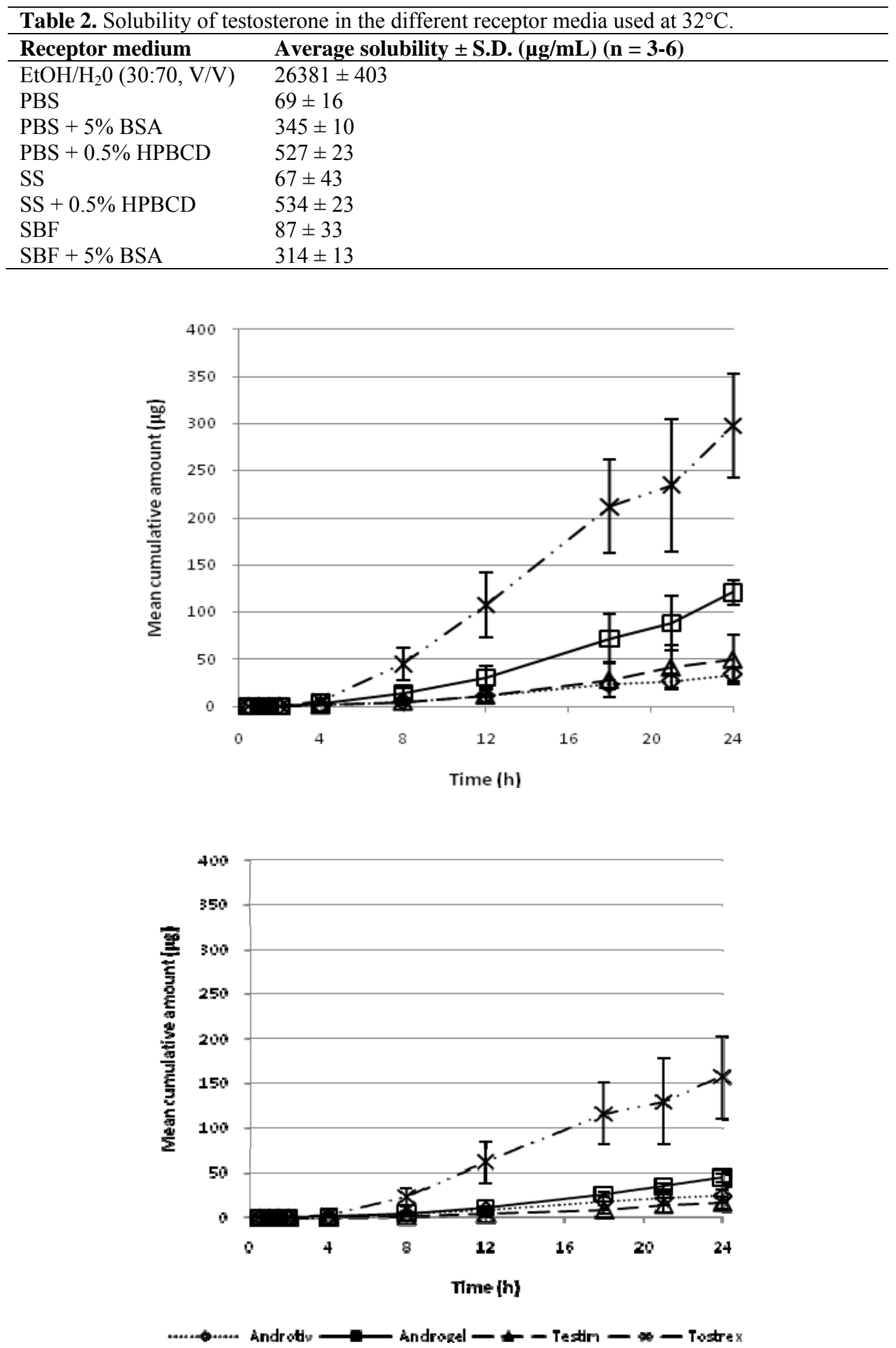

Figure 1. Cumulative amount of testosterone in the receptor fluid $(\mu \mathrm{g})$ versus time $(\mathrm{h})$ curves using human skin and PBS + HPBCD (upper panel) or PBS + BSA (lower panel) as a receptor fluid. 


\begin{tabular}{|c|c|c|c|c|c|c|}
\hline Parameter & Gel & EtOH/H $/ \mathrm{H}_{2} \mathrm{O}$ & PBS + 5\% BSA & $\begin{array}{c}\text { PBS + 0.5\% } \\
\text { HPBCD } \\
\end{array}$ & $\mathrm{SBF}+5 \% \mathrm{BSA}$ & $\begin{array}{c}\text { SS + 0.5\% } \\
\text { HPBCD }\end{array}$ \\
\hline \multirow{4}{*}{$\begin{array}{c}\text { Skin } \\
\mathrm{Kp} \\
\left(\mathrm{x} 10^{-4} \mathrm{~cm} / \mathrm{h}\right)\end{array}$} & Androtiv & $2.75 \pm 0.10$ & $1.07 \pm 0.05$ & $1.40 \pm 0.07$ & $1.29 \pm 0.04$ & $2.05 \pm 0.07$ \\
\hline & Androgel $^{\circ}$ & $4.08 \pm 0.27$ & $3.98 \pm 0.26$ & $10.29 \pm 0.81$ & $4.14 \pm 0.44$ & $8.03 \pm 0.66$ \\
\hline & Testim & $0.50 \pm 0.06$ & $1.50 \pm 0.13$ & $4.53 \pm 0.35$ & $1.16 \pm 0.13$ & $5.89 \pm 0.38$ \\
\hline & Tostrex ${ }^{\oplus}$ & $16.91 \pm 0.76$ & $6.20 \pm 0.24$ & $11.53 \pm 0.50$ & $6.73 \pm 0.41$ & $22.41 \pm 0.99$ \\
\hline \multirow{4}{*}{$\begin{array}{c}\text { Skin } \\
\mathrm{T}_{\text {lag }}(\mathrm{h})\end{array}$} & Androtiv ${ }^{\circledR}$ & 3.13 & 5.44 & 5.48 & 3.64 & 2.77 \\
\hline & Androgel ${ }^{\oplus}$ & 5.87 & 7.07 & 6.72 & 7.04 & 7.34 \\
\hline & Testim & 5.43 & 7.66 & 7.26 & 10.75 & 7.50 \\
\hline & Tostrex & 3.58 & 4.23 & 4.30 & 4.97 & 4.11 \\
\hline \multirow{4}{*}{$\begin{array}{c}\text { Membrane } \\
\text { Initial } \\
\mathrm{Kp} \\
\left(\times 10^{-4} \mathrm{~cm} / \mathrm{h}\right)\end{array}$} & Androtiv & $27.93 \pm 0.47$ & $2.15 \pm 0.18$ & $7.91 \pm 0.69$ & $1.42 \pm 0.15$ & $9.77 \pm 1.22$ \\
\hline & Androgel & $90.16 \pm 1.29$ & $5.30 \pm 0.47$ & $5.86 \pm 0.49$ & $5.61 \pm 0.61$ & $5.95 \pm 0.54$ \\
\hline & Testim & $45.05 \pm 1.02$ & $2.62 \pm 0.28$ & $3.41 \pm 0.19$ & $4.18 \pm 0.47$ & $2.48 \pm 0.15$ \\
\hline & Tostrex ${ }^{\oplus}$ & $26.81 \pm 0.82$ & $30.07 \pm 0.44$ & $45.41 \pm 0.16$ & $28.33 \pm 0.20$ & $57.10 \pm 0.20$ \\
\hline \multirow{4}{*}{$\begin{array}{c}\text { Membrane } \\
\text { Initial } \\
\mathrm{T}_{\text {lag }}(\mathrm{h})\end{array}$} & Androtiv ${ }^{\circledR}$ & 0.20 & 0.51 & 0.56 & 0.37 & 0.53 \\
\hline & Androgel $^{\circledR}$ & 0.17 & 0.48 & 0.54 & 0.53 & 0.50 \\
\hline & Testim & 0.11 & 0.63 & 0.42 & 0.32 & 3.63 \\
\hline & Tostrex ${ }^{\oplus}$ & 0.09 & 0.21 & 0.26 & 0.31 & 0.23 \\
\hline \multirow{4}{*}{$\begin{array}{l}\text { Membrane } \\
\text { Final Kp } \\
\left(\times 10^{-4} \mathrm{~cm} / \mathrm{h}\right)\end{array}$} & Androtiv ${ }^{\oplus}$ & $8.89 \pm 0.55$ & $7.28 \pm 0.40$ & $24.50 \pm 2.71$ & $6.93 \pm 0.13$ & $29.72 \pm 0.68$ \\
\hline & Androgel $^{\oplus}$ & $39.27 \pm 1.31$ & $26.55 \pm 0.95$ & $39.91 \pm 2.99$ & $27.11 \pm 0.77$ & $37.60 \pm 3.87$ \\
\hline & Testim & $28.59 \pm 0.68$ & $7.89 \pm 0.33$ & $64.04 \pm 3.71$ & $8.49 \pm 0.44$ & $56.08 \pm 1.24$ \\
\hline & Tostrex ${ }^{\circledR}$ & $6.90 \pm 0.49$ & $14.81 \pm 1.06$ & $20.32 \pm 0.40$ & $21.15 \pm 1.50$ & $24.26 \pm 0.76$ \\
\hline
\end{tabular}

\section{Franz diffusion cell experiments using artificial membranes}

In addition to the dermatomed human skin approach, the four formulations were tested in triplicate on Franz diffusion cells using an artificial membrane as diffusion barrier and again, the cumulative amount of testosterone in the receptor fluid was plotted against time (Figure 2).

In contrast to the skin experiments, the data obtained could not be modelled directly over the complete 24 hours experimental domain by the standard steady-state linear regression due to the non-linear behaviour, with an initial linear part, a bending point region (22) and a final linear part. However, both selected linear time-regions were suitable for separate linear regression analysis: the initial 2 hours and from 8 till 24 (final) hours.

Moderate to good linear coefficients of determination ( $\mathrm{R}^{2}$ ranging from 0.9296 to 0.9999 ) were obtained for both selected time regions and therefore, initial and final Kp-values were calculated from both experimentally obtained $\mathrm{J}$ values as before (Table 3). As expected, lag times for the initial linear part of the membrane studies were much lower compared to the human skin penetration behaviour.

\section{Values of the discriminating power criterion}

The calculated values for the response function $\mathrm{F}(\mathrm{Kp})$ are given in Table 4 . Values are ranging from $0.12 \%$, indicating that this FDC system is not capable of discriminating the different formulations, to $28 \%$ where a different behaviour of the formulations could be observed. For quality control (QC) purposes, the systems with the highest $\mathrm{F}(\mathrm{Kp})$ values are preferred, as these will be the most discriminating.

\section{DISCUSSION}

Being able to consistently observe differences in transdermal/membrane behaviour of similar transdermal products is useful in quality control (QC) environment, where the concept of clinically overdiscriminating in vitro tests is superfluous: whenever significant differences are observed, 

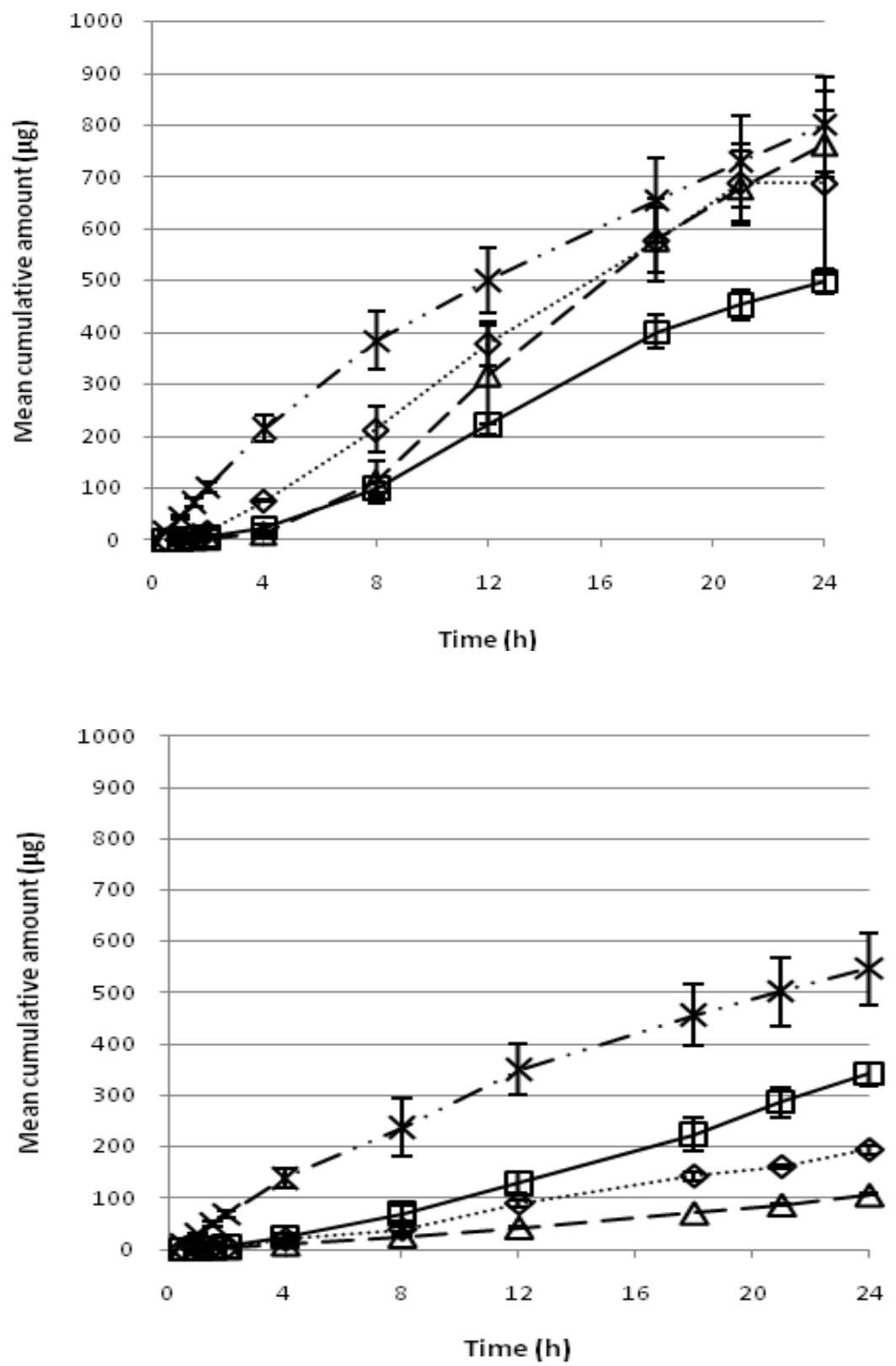

…..... Androtiv $\longrightarrow$ Androgel $-\star-$ Testim $-*-$ Tostrex

Figure 2. Cumulative amount of testosterone in the receptor fluid ( $\mu \mathrm{g})$ versus time (h) curves using artificial membranes and PBS + HPBCD (upper panel) or PBS + BSA (lower panel) as a receptor fluid.

pharmaceutical non-equivalence should be concluded. For this QC-objective, we were especially looking at the discriminating power of the Franz diffusion cell methods, which are recommended as global quality tests for transdermal products, similar to dissolution for oral solid dosage forms. To evaluate this discriminating aspect in an objective and quantitative way, a new criterion $\mathrm{F}(\mathrm{Kp})$ is proposed: the percentage equal-spread of the rescaled $\mathrm{Kp}$ values obtained in the different conditions investigated. We have evaluated the practical usefulness of this criterion in a study evaluating the choice of the receptor fluid. 
Table 4. $\mathrm{F}(\mathrm{Kp})$ values (percentage spreading) on normalized Kp values for the testosterone preparations investigated $(\mathrm{n}=$ 4).

\begin{tabular}{llllll}
\hline \multirow{2}{*}{ Membrane System } & \multirow{2}{*}{ EtOH/H $\mathbf{H} \mathbf{O}$} & $\begin{array}{l}\text { PBS + 5\% } \\
\text { BSA }\end{array}$ & $\begin{array}{l}\text { PBS + } \\
\text { HPBCD }\end{array}$ & $\begin{array}{l}\text { SBF + 5\% } \\
\text { BSA }\end{array}$ & $\begin{array}{l}\text { SS + } \\
\text { HPBCD }\end{array}$ \\
\hline Skin Kp & 9.42 & 0.58 & 7.13 & 0.47 & 28.04 \\
Membrane initial Kp & 3.46 & 0.12 & 0.75 & 0.36 & 2.50 \\
Membrane final Kp & 6.23 & 0.74 & 23.18 & 1.75 & 11.85 \\
\hline
\end{tabular}

\begin{tabular}{|c|c|c|c|}
\hline Formulation & Receptor fluid & Kp $\left(10^{-4} \mathrm{~cm} / \mathrm{h}\right) \pm$ S.D. & $\mathbf{F ( K p )}$ \\
\hline $65 \% \mathrm{EtOH}$ & & $4.38 \pm 2.82$ & \\
\hline $10 \%$ PG & PBS & $15.34 \pm 1.50$ & 14.08 \\
\hline Commercial extract & & $3.56 \pm 2.17$ & \\
\hline $65 \% \mathrm{EtOH}$ & & $4.38 \pm 2.84$ & \\
\hline $10 \% \mathrm{PG}$ & PBS + HPBCD & $16.62 \pm 1.85$ & 10.42 \\
\hline Commercial extract & & $4.95 \pm 3.31$ & \\
\hline $65 \%$ EtOH & & $0.70 \pm 0.25$ & \\
\hline $10 \% \mathrm{PG}$ & $\mathrm{EtOH} / \mathrm{H}_{2} \mathrm{O}$ & $5.46 \pm 1.60$ & 0.45 \\
\hline Commercial extract & & $0.64 \pm 0.31$ & \\
\hline
\end{tabular}

\section{Spilanthol application}

Based upon the $\mathrm{Kp}$ values as experimentally obtained (18), the $\mathrm{F}(\mathrm{Kp})$ values were calculated for each of the three FDC test systems (Table 5).

The choice of the receptor solution is indeed an important determinant in the design of an in vitro model for percutaneous penetration, as the receptor phase interacts directly with the membrane (artificial or skin) and eventually with the formulation in the donor phase, as well as collects the drug penetrated through the skin/membrane (23). Depending upon the test conditions chosen, different conclusions about the release/permeation characteristics of the formulation can be made (24). The generally accepted OECD Guideline Number 428 on the Conduct of Skin Absorption Studies states that the selection of the receptor fluid must be compatible with the skin preparation and must meet the solubility requirements of the test substance (5). No further details on how this should be translated in practice are given. Therefore, researchers are free to choose the receptor medium they prefer for their selected application and intended objective. An overview of the most commonly used receptor media in recent (2007-2008) in vitro transdermal penetration literature studies $(n=104)$ is given in Figure 3. The base solvent (left graph) is often supplemented by additives (right graph), mostly to increase the solubility of the test substance to obtain sink conditions or to increase the stability of the system. Phosphate buffers, often resembling physiological conditions, are the most often used base solvents $(60 \%)$, followed by non-buffered water $(15 \%)$ or normal saline (sodium chloride) solutions (15\%). Often, these phosphate buffers are derived from and are similar to those used in dissolution tests for oral dosage forms (25). To prevent bacterial degradation of the drug under investigation (26), antimicrobial preservative agents are used as an additive in $15 \%$ of the cases. Besides the maintenance of skin viability and integrity, a major requirement of the receptor fluid is to assure sufficient solubility of the test substance in order for the solubility not to limit the penetration (27). When the transdermal behaviour of compounds with low aqueous solubility is to be assessed, different solubilizers can be used to increase the solubility of the drug in the aqueous receptor medium while limiting skin interaction. Solubilization of poorly water soluble drugs is a frequently encountered challenge in the pharmaceutical industry and a number of solubilisation techniques have been developed (28). The solubility of poorly water soluble drugs can be increased by the addition of a water miscible solvent in which the drug has a good solubility. In transdermal penetration studies, solubility-increasing additives are used in 36\% $(n=37)$ of the literature reports. In these studies, 

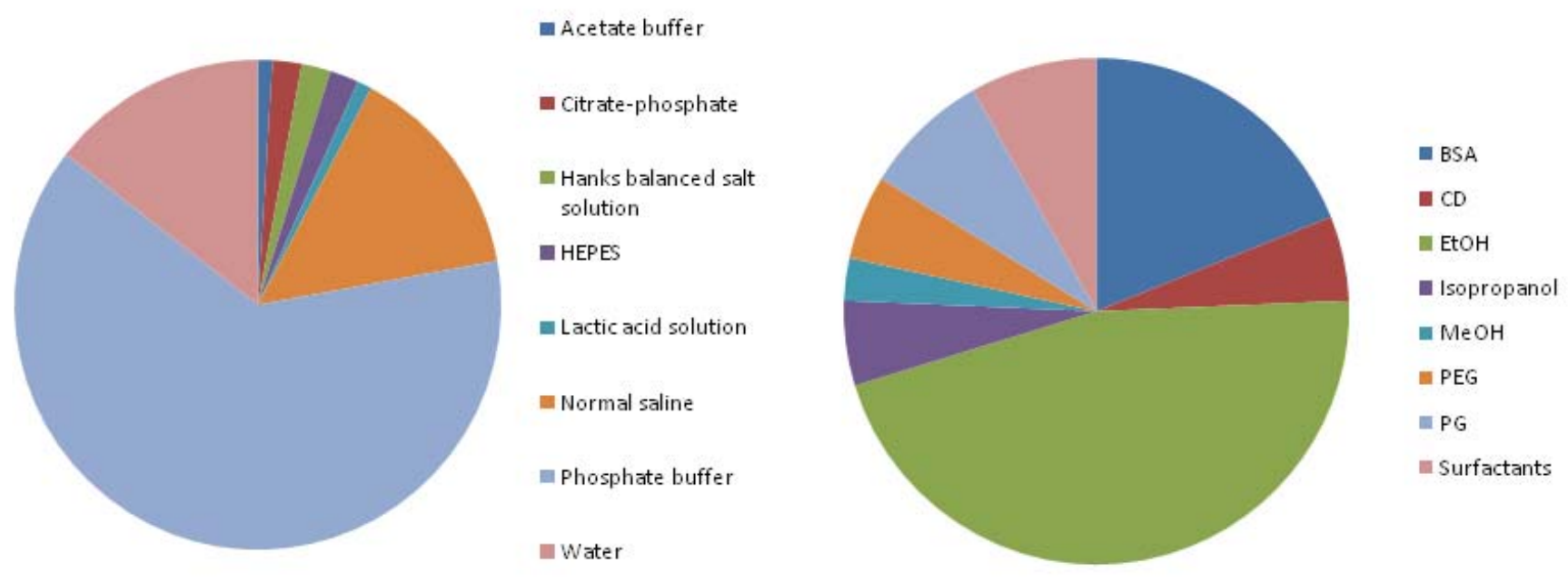

Figure 3. Overview of receptor media used in transdermal penetration studies. Left: base solvents. Right: solubilityincreasing additives.

EtOH is most frequently used as a co-solvent $(46 \%)$, but other solvents such as propylene glycol (PG) (8\%), polyethylene glycol (PEG) (5\%), isopropanol $(5 \%)$, and even methanol $(3 \%)$ are being employed. In $8 \%$ of the recent studies reported in the literature (period 2007-2008), surfactants like Tween $20^{\circledR}$ or Brij $98^{\circledR}$ have been used as a modifier to ensure adequate solubility of the test compound. Albumin binds a wide variety of hydrophobic ligands, including steroids, fatty acids, retinoids, thyroid hormone, prostaglandins and antibiotics (29). Because serum contains around 3 to $5 \% \mathrm{~m} / \mathrm{V}$ albumin (21), addition of similar quantities BSA to the receptor medium contributes to its in vivo relevance. It is also recommended by the OECD as a solubilising agent and was used in almost $20 \%$ of the recent studies to increase solubility of lipophilic compounds. Alternatively, cyclodextrins can be used as they possess a lipophilic cavity and a hydrophilic exterior, thus making them ideal to form inclusion complexes with non-polar molecules in relatively polar solvents like water (30). This complexation has been applied as one of the most useful ways to improve the dissolution of poorly water-soluble drugs in intravenous and oral formulations (31). Up till now, they are only scarcely used in Franz diffusion cell experiments (approximately $5 \%$ of the literature studies), but are promising as solubilizing agents in the field. HPBCD is a chemically modified cyclodextrin with high aqueous solubility (32). It is already successfully used in transdermal formulations (33), as well as in dissolution media for the evaluation of tablets for oral use (34).

When using human/animal skin, interactions of the receptor medium with the contacting lower skin layers can modify these layers (e.g. precipitation of proteins or dissolution of specific endogenous skin compounds) and consequently, the apparent diffusion characteristics of the skin for the test compound can change. This is not the case when using artificial membranes, which remain inert towards the receptor medium composition. In this case, a more direct interaction of the receptor medium with the formulation itself is expected. The homogeneous artificial membrane is thus more a passive diffusion barrier only, while the heterogeneous skin can additionally have an active role. While the above considerations are important in IVIVR, assuring product consistency during development and marketing is the key concern in pharmaceutical quality, with no obligatory link to the in vivo relevance. Therefore, in the QC-field, tests are expected to be maximally discriminating. The criterion $\mathrm{F}(\mathrm{Kp})$ is a measure for the percentage spread of the normalised $\mathrm{Kp}$ values obtained in the different conditions investigated. It can be used to evaluate the discriminating effect of the FDC 
method, i.e. the ability to distinguish different preparations as separate items. The maximal $\mathrm{F}(\mathrm{Kp})$ value that can be reached theoretically is $100 \%$, meaning that the Kp-values obtained are maximally different. On the other hand, if the Kp-values found for two different preparations are identical, the test is not discriminating and the $\mathrm{F}(\mathrm{Kp})$ value obtained in this situation will be zero. In other words, the $\mathrm{F}(\mathrm{Kp})$ value indicates how the operational conditions employed during FDC experiments affect the ability of the test to discriminate different preparations.

Using our criterion $\mathrm{F}(\mathrm{Kp})$, the lowest responses were obtained with the membrane initial $\mathrm{Kp}$ values. Therefore, irrespective of the receptor medium used, only drastic changes in the diffusion behaviour can be seen on initial membrane Kp values, while less pronounced effects are masked and not differentiated. Despite the fact that the evaluation of the initial kinetics has the advantage of not being influenced by solubility constraints and of a relatively short time period which is well suited for QC purposes, our criterion quantitatively shows this approach is not useful. When considering skin $\mathrm{Kp}$ or membrane final $\mathrm{Kp}$ values, a better spreading and hence discriminating power was observed. Depending upon the type of receptor medium used, differences in the discriminating power of the testosterone FDC experiments were observed (Table 4). The highest discriminating response was obtained using $0.5 \%$ HPBCD containing media (up to $28.04 \%$ ), while the discriminative power of the test was relatively small when using BSAcontaining media $(<1.75 \%)$. For $\mathrm{EtOH} / \mathrm{H}_{2} \mathrm{O}$, the $\mathrm{F}(\mathrm{Kp})$ value was intermediate (up to $9.42 \%$ ). A different situation was observed for the spilanthol samples (Table 5): best discriminating results were obtained using PBS without solubilizers as a receptor medium (14.08\%), followed by PBS containing $0.5 \% \mathrm{~m} / \mathrm{V}$ HPBCD $(10.42 \%)$. When using $\mathrm{EtOH} / \mathrm{H} 20(30 / 70, \mathrm{~V} / \mathrm{V})$, the test was not discriminative $(0.45 \%)$.

\section{CONCLUSIONS}

For quality purposes of transdermal products, a quantitative and objective discriminative power criterion is proposed based upon the observed spreading of $\mathrm{Kp}$-values. This criterion is a simple, reliable and reproducible characteristic that is experimentally obtained from the generally accepted Franz diffusion cell test for the assessment of the transdermal behaviour of molecules. The practical applicability was demonstrated by evaluating the influence of the receptor medium composition on the discriminative power of the test system for both testosterone and spilanthol containing formulations. The best results were obtained with PBS supplemented with HPBCD for testosterone and without HPBCD for spilanthol.

\section{ACKNOWLEDGEMENTS}

The authors would like to thank Sudhakar Annavarapu and Ann De Meulemeester for their technical assistance.

\section{ABBREVIATIONS}

$\begin{array}{ll}\text { AAPS } & \text { American Association of } \\ & \begin{array}{l}\text { Pharmaceutical Scientists } \\ \text { Active Pharmaceutical Ingredient }\end{array} \\ \text { BSA } & \begin{array}{l}\text { Bovine Serum Albumin } \\ \text { CDclodextrine }\end{array} \\ \text { COLIPA } & \begin{array}{l}\text { European Cosmetic Toiletry and } \\ \text { Perfumery Association }\end{array} \\ \text { ECETOC } & \begin{array}{l}\text { European Centre for Ecotoxicology } \\ \text { and Toxicology of Chemicals }\end{array} \\ \text { EtOH } & \text { Ethanol } \\ \text { FDA } & \text { Food and Drug Administration } \\ \text { FDC } & \text { Franz Diffusion Cell } \\ \text { HPBCD } & \text { Hydroxypropyl- } \beta \text {-cyclodextrine } \\ \text { IVIVR } & \text { In Vitro-In Vivo Relationship } \\ \text { Kp } & \text { Permeability Coefficient } \\ \text { MeOH } & \text { Methanol } \\ \text { OECD } & \text { Organisation for } \\ & \text { Cooperation and Development } \\ \text { PEG } & \text { Polyethylene Glycol } \\ \text { PG } & \text { Propylene Glycol } \\ \text { QC } & \text { Quality Control } \\ \text { S.D. } & \text { Standard deviation } \\ \text { TDS } & \text { Transdermal Delivery System }\end{array}$

\section{REFERENCES}

1. Shah, V.P.; Peck C.C.; Williams R.L., Skin Penetration Enhancement - Clinical Pharmacological and Regulatory Considerations, in Walters KA: Hadgraft J (eds), Pharmaceutical Skin Penetration Enhancement. Marcel Dekker, Inc., New York, NY, pp.417-427, 1993.

2. Shah, V.P., Ludden, T.M., Dighe, S.V., Skelly, J.P. and Williams, L., Bioavailability and 
Bioequivalence of Transdermal Drug Delivery Systems: Regulatory Considerations, in Shah VP: Maibach HI (eds), Topical Drug Bioavailability, Bioequivalence and Penetration. Plenum Press, New York, NY, pp 415-424, 1993.

3. Rosen, M.R.; Delivery System Handbook for Personal Care and Cosmetic Products: Technology, Applications and Formulations. William Andrew Publishing, Norwich, NY, USA, 2005.

4. Carrara, D.N. and Porto, G., Development of Transdermal Products, in Bonate P: Howard D (eds), Pharmacokinetics in Drug Development: Regulatory and Developmental Paradigms. AAPS Press, Arlington, VA, pp. 423-470, 2004.

5. OECD. OECD series on testing and assessment Guidance document for the conduct of skin absorption studies. 2004.

6. ECETOC. Monograph Report No 20: Percutaneous Absorption. 1993.

7. COLIPA. Cosmetic Ingredients: Guidelines for Percutaneous Absorption / Penetration. 1997.

8. J.P. Skelly, V.P. Shah, H.I. Maibach, R.H. Guy, R.C. Wester, G. Flynn and A. Yacobi. FDA and AAPS Report of the Workshop on Principles and Practices of In vitro Percutaneous Penetration Studies - Relevance to Bioavailability and Bioequivalence. Pharm Res, 4, 265-267, 1987.

9. U.S. Department of Health and Human Services, Food and Drug Administration, Center for Drug Evaluation and Research (CDER). Guidance for Industry on Nonsterile Semisolid Dosage Forms Scale-Up and Postapproval Changes: Chemistry, Manufacturing, and Controls, In Vitro Release Testing and In Vivo Bioequivalence Documentation. 1997.

10. T.S. Poet and J.N. McDougal. Skin absorption and human risk assessment. Chem-Biol Interact, 140:1934, 2002.

11. McCleverty, D; Lyons, R.; Henry, B., An Industry Perspective of Topical Dermal Bioequivalence, in Roberts MS: Walters KA (eds). Dermal Absorption and Toxicity Assessment. 2nd ed., Informa Healthcare, Inc, New York, NY, pp 549-561, 2008.

12. Tamara V.K., Baweja R.K., Dorantes A., Hunt J.P., Pelsor F.R., Sun, H., Shah V.P. and Wilkin, J.K., Biopharmaceutical Considerations for Topical and Transdermal Drug Delivery Systems, in Ghosh TK, Pfister WR and Yum S (eds), Transdermal and Topical Drug Delivery Systems. Interpharm, Inc, Buffalo Grove, IL, pp 629-658, 1997.

13. G.L. Flynn, ,V.P. Shah, S.N. Tenjarla, M. Corbo, D. DeMagistris, T.G. Feldman, T.J. Franz, D.R. Miran, D.M. Pearce, J.A. Sequeira, J. Swarbrick, J.C.T. Wang, A. Yacobi and J.L. Zatz. Assessment of Value and Applications of In Vitro
Testing of Topical Dermatological Drug Products. Pharm. Res., 16(9): 1325-1330, 1999.

14. B. Baert, E. Deconinck, M. Van Gele, M. Slodicka, P. Stoppie, S. Bodé, G. Slegers, Y. Vander Heyden, J. Lambert, J. Beetens and B. De Spiegeleer. Transdermal penetration behaviour of drugs: CARTclustering, QSPR and selection of model compounds. Bioorg Med Chem, 15:6943-6955, 2007.

15. B. Baert ,S. Annavarapu, C. Burvenich and B. De Spiegeleer. Analytical, biopharmaceutical and regulatory evaluation of topical testosterone preparations. Eur J Pharm Biopharm, 72:275-281, 2009.

16. T. Shimamura, T. Tairabune, T. Kogo, H. Ueda, S. Numajiri, D. Kobayashi and Y. Morimoto. Investigation of the release test method for the topical application of pharmaceutical preparations: Release test of cataplasm including nonsteroidal anti-inflammatory drugs using artificial sweat. Chem Pharm Bull, 52:167-171, 2004.

17. S.V. Dorozhkin and E.I. Dorozhkina. The influence of bovine serum albumin on the crystallization of calcium phosphates from a revised simulated body fluid. Colloid Surf A-Physicochem Eng Asp, 215:191-199, 2003.

18. J. Boonen, B. Baert, N.Roche, C. Burvenich, B. De Spiegeleer. Transdermal behaviour of the Nalkylamide spilanthol (affinin) from Spilanthes acmella (Compositae) extracts. J. Ethnopharmacol., 127:77-84, 2010.

19. J.Boonen, B. Baert, C. Burvenich, P. Blondeel, S. De Saeger, B. De Spieleer. LC-MS profiling of Nalkylamides in Spilanthes acmella extract and the transmucosal behaviour of its main bio-active spilanthol. J. Pharm. Biomed. Anal. Doi:10.1016/j.jbba.2010.02.010, 2010

20. Shah, V.P., The role of dissolution testing in the regulation of pharmaceuticals: the FDA perspective, in: Dressman, J: Kramer, J. (eds), Pharmaceutical Dissolution Testing, Taylor \& Francis Group, Boca Raton, FL, pp 81-96, 2005.

21. B.T. Veering, A.G.L. Burm, J.H.M. Souverijn, J.M.P. Serree and J. Spierdijk. The Effect of Age on Serum Concentrations of Albumin and Alpha-1Acid Glycoprotein. Br J Clin Pharmacol, 29:201206, 1990.

22. L. Van Vooren, G. Krikilion, J. Rosier and B. De Spiegeleer. A novel bending point criterion for dissolution profile interpretation. Drug Dev Ind Pharm, 27:885-892, 2001.

23. P. Sartorelli, H.R. Andersen, J. Angerer, J. Corish, H. Drexler, T. Goen, P. Griffin, S.A.M. Hotchkiss, F. Larese, L. Montomoli, J. Perkins, M. Schmelz, J. van de Sandt and F. Williams. Percutaneous 
penetration studies for risk assessment. Environ Toxicol Pharmacol, 8:133-152, 2000.

24. S. Proniuk, S.E. Dixon and J. Blanchard. Investigation of the utility of an in vitro release test for optimized semisolid dosage forms. Pharmaceutical Development and Technology, 6(3): 469-476, 2001.

25. B. De Spiegeleer, B. Baert, E. Vangheluwe, I. Becue, J. De Smet,P. Spanoghe, C. Wille, P. Van der Meeren and G. Slegers. Comparison of the wetting properties of three commonly used simulated intestinal fluids used as dissolution media in the characterization of drugs. J Solut Chem, 36: 835843, 2007.

26. S. Bode, B. Baert, M. Van Gele, J. Lambert, C. Burvenich, G. Slegers and B. De Spiegeleer. Stability of the OECD model compound benzoic acid in receptor fluids of Franz diffusion cells. Pharmazie, 62:470-471, 2007.

27. Sequeira, J.A., Optimization of the Skin Availability of Topical Products, in Zatz JL (ed), Skin Permeation: Fundamentals and Application. Allured Publishing Corporation, Wheaton, IL, pp.163-176, 1993.

28. S. Mallick, S. Pattnaik and K. Swain. Current perspectives of solubilization: Potential for improved bioavailability. Drug Dev Ind Pharm, 33:865-873, 2007.

29. M.E. Baker. Albumin, steroid hormones and the origin of vertebrates. J Endocrinol, 175:121-127, 2002.

30. M.E. Brewster and T. Loftsson. Cyclodextrins as pharmaccutical solubilizers. Adv Drug Deliv Rev, 59:645-666, 2007.

31. K. Hussein, M. Turk and M.A. Wahl. Comparative evaluation of ibuprofen/beta-cyclodextrin complexes obtained by supercritical carbon dioxide and other conventional methods. Pharm Res, 24:585-592, 2007.

32. C.L. Kear, J. Yang, D.A. Godwin and L.A. Felton. Investigation into the mechanism by which cyclodextrins influence transdermal drug delivery. Drug Dev Ind Pharm, 34: 692-697, 2008.

33. S.N. Murthy, Y.L. Zhao, A. Sen and S.W. Hui. Cyclodextrin enhanced transdermal delivery of piroxicam and carboxyfluorescein by electroporation. J Contr Rel, 99:393-402, 2004.

34. B. De Spiegeleer, L. Van Vooren, J. Voorspoels, D. Thone and J. Rosier. Dissolution stability and IVIVC investigation of a buccal tablet. Anal. Chim Acta, 446:345-351, 2004. 